\title{
The epidural structure changes during deep breathing
}

\author{
Takashi Igarashi MD, \\ Yoshihiro Hirabayashi MD, \\ Reiju Shimizu MD, \\ Kazuhiko Saitoh MD, \\ Hirokazu Fukuda MD
}

Purpose: Previous experience has suggested that the insertion of an epidural catheter becomes easier when the patient takes a deep breath. The purpose of this study is to investigate the effects of respiration on the epidural space. Methods: We examined the epidural space using a fexible epiduroscope in 20 patients undergoing thoracic epidural anesthesia. A 17-gauge Tuohy needle was inserted using the paramedian technique and the loss-of-resistance method with $5 \mathrm{ml}$ air. The epiduroscope was introduced into the epidural space via the Tuohy needle. Each patient was requested to take a deep breath when the epiduroscope was positioned at the needle tip and at approximately $10 \mathrm{~cm}$ cephalad from the needle tip within the epidural space. The changes in the epidural structure during deep breathing at each site were then measured.

Results: In $80 \%$ of the patients, fatty tissue occupied the needle tip. Through the patients' maximal inspiration. the fatty tissue moved and a visible cavity expanded at the needle tip. Cross section area of the visible cavity at the needle tip was greater at the maximal inspiratory level than at the resting expiratory level: $12.1 \pm 6.7 \%$ vs $2.8 \pm 2.1 \%$ (mean $\pm \mathrm{SD}, P<0.0001$ ). In all patients, the visible cavity within the epidural space, which had already been expanded by injected air, became more expanded after maximal inspiration. Cross section area of the visible cavity at the $10 \mathrm{~cm}$ cephalad position was greater at the maximal inspiratory level than at the resting expiratory level: $20.6 \pm 10.0 \%$ vs $7.0 \pm 5.3 \%(P<0.0001)$.

Conclusion: Epiduroscopy showed that deep breathing expanded the potential cavity of the epidural space. We suggest that the changes in the epidural structure during deep breathing may assist in the insertion of an epidural catheter.

Objectif : L'expérience antérieure nous a suggéré que l'insertion d'un cathéter épidural est plus facile quand le patient inspire profondément. L'objectif de notre étude est d'examiner les effets de la respiration sur l'espace épidural.

Méthode : Nous avons examiné l'espace épidural au moyen d'un épiduroscope flexible chez 20 patients devant subir une anesthésie péridurale thoracique. Une aiguille Tuohy de calibre 17 a été insérée selon la technique paramédiane et la méthode de perte de résistance avec $5 \mathrm{ml}$ d'air. L'épiduroscope a été introduit dans l'espace épidural au travers de l'aiguille Tuohy. On a demandé à chaque patient de respirer profondément au moment du positionnement de l'épiduroscope à la pointe de l'aiguille et à $10 \mathrm{~cm}$ environ en direction céphalique, par rapport à la pointe de l'aiguille, à l'intérieur de l'espace épidural. On a mesuré les changements de structure épidurale survenus pendant la respiration profonde à chaque site.

Résultats : Chez 80 \% des patients, le tissu adipeux a rempli la pointe de l'aiguille. Pendant l'inspiration maximale, le tissu adipeux s'est déplacé et une cavité visible est apparue à la pointe de l'aiguille. L'aire transversale de la cavité visible à la pointe de l'aiguille était plus grande lors de l'inspiration maximale qu'au repos expiratoire: 12,1 $\pm 6,7 \%$ vs 2,8 $\pm 2,1 \%$ (moyenne \pm écart-type, $P<0,0001$ ). Chez tous les patients, la cavité visible à l'intérieur de l'espace épidural, déjà agrandie par une injection d'air, s'est encore agrandie après l'inspiration maximale. L'aire transversale de la cavité visible à $10 \mathrm{~cm}$ en direction céphalique était plus grande lors de l'inspiration maximale qu'au repos expiratoire : $20,6 \pm 10,0 \%$ vs $7,0 \pm 5,3 \% P<0,0001$ ).

Conclusion : L'épiduroscopie a montré que l'inspiration profonde augmente la cavité potentielle de l'espace épidural. Nous croyons que les modifications de la structure épidurale pendant la respiration profonde peuvent faciliter l'insertion d'un cathéter épidural.

From the Department of Anesthesiology, Jichi Medical School, 3311-1 Yakushiji, Minamikawachi-machi, Kawachi-gun, Tochigi-ken 329 0498, Japan.

Address correspondence to: Dr. Takashi Igarashi. Phone: $+81-285-58-7383 ;$ Fax: $+81-285-44-4108$.

Accepted for Publication June 10, 1999 
EEP breathing as a strategy for assistance in epidural catheter insertion has occasionally been experienced in clinical situations. ${ }^{1}$ However, the reasons for this have not been well investigated. The passage of the epidural catheter can be influenced by the angle of the needle relative to the dorsal plane of the skin, the location of the needle tip and the structure of the epidural space. The existence of fatty tissue and fibrous connective tissue within the epidural space ${ }^{2-4}$ can also impede catheter passage. Since the epidural space is described as a potential space, rather than a true cavity ${ }^{5-7}$ we speculated that the epidural structure may alter during deep breathing and that the alterations may assist in epidural catheter insertion. Few studies have described the effects of deep breathing on the epidural space while coughing is reported to increase epidural pressure. ${ }^{8}$ Since epiduroscopy provides a clear view of the epidural space, ${ }^{4,5,9-11}$ we used the technique to investigate the structural changes during deep breathing.

\section{Patients and methods}

This study was approved by our Local Ethics Committee and informed consent was obtained from all patients. We examined the epidural space with a flexible fibrescope in 20 patients undergoing thoracic epidural anesthesia for a variety of upper and lower abdominal operations. Patients with a history of previous epidural anesthesia, pregnancy, neurological disease, abnormalities of vertebral column or abdominal distension were excluded.

Each patient was premedicated with 0.25 to $0.5 \mathrm{mg}$ atropine $i m$ and 25 to $50 \mathrm{mg}$ hydroxyzine $i m$. The patient was placed in the right lateral decubitus position on a horizontal operating table. A 17-gauge Tuohy needle (Becton-Dickinson Co., NJ, USA) was introduced at one point between the $\mathrm{Th}_{7-10}$ interspace, using the paramedian technique. The epidural space was identified using the loss-of-resistance method with $5 \mathrm{ml}$ air. When no cerebrospinal fluid or blood flowed from the needle, a flexible fibrescope measuring $0.7 \mathrm{~mm}$ in diameter (Igarashi Ika Kogyo Co., MS-501, Tokyo, Japan) connected to a television monitor system (Igarashi Ika Kogyo Co., FV-2000E) was introduced in a cephalad direction into the epidural space via the Tuohy needle. Each patient was requested to take a deep breath to maximal inspiratory level but not to hold the inspiration, when the epiduroscope was advanced to the tip of the Tuohy needle and to approximately $10 \mathrm{~cm}$ in a cephalad direction from the needle tip within the epidural space. The changes in the epidural structure during deep breathing were then examined. Cross sec- tion area of the visible epidural cavity was measured at the patients' resting expiratory and maximal inspiratory levels. ${ }^{12}$ Cross section area was expressed as a ratio of the visible area of the epiduroscope. The epiduroscope was held in position during deep breathing. If paresthesia or resistance was noted during epiduroscope insertion, no attempt was made to advance the epiduroscope through the area of resistance. No more air was injected after insertion of the epiduroscope into each patient. After epiduroscopic examination, an epidural catheter (outside diameter, $0.85 \mathrm{~mm}, \mathrm{~B}$. Brown Co., PA, USA) was inserted $5 \mathrm{~cm}$ in a cephalad direction into the epidural space. All procedures were performed by the same anesthesiologist. The patients received local anesthetics via the catheter during the planned therapeutic or surgical procedure along with general anesthesia.

Epiduroscopic findings were videotaped during the fibrescopic examination in each patient. The epidural cross section area images at maximal inspiratory level and at resting expiratory level were scanned into a personal computer (Macintosh Quadra 650, Apple Computer Inc., CA, USA) and were measured using image analysis software (NIH image V1.6, written by Wayne Rasband at US National Institute of Health, VA, USA). The statistical analyses were carried out using a statistical software package (StatView V4.05, Abacus Concepts, CA, USA). The Mann-Whitney's U test was used to analyze the differences in the epidural cross section area between the respiratory levels of resting expiration and of maximal inspiration. A $P$ value less than 0.05 was considered statistically significant.

\section{Results}

Mean ( \pm SD) age, height and weight of the patients were $63 \pm 11 \mathrm{yr}, 159 \pm 7 \mathrm{~cm}$ and $57 \pm 9 \mathrm{~kg}$ respectively. The epiduroscopic examination was successfully performed in all patients. Dura mater, ligamentum flavum, fatty tissue, other connective tissue and the epidural space expanded by injected air were observed. We encountered no accidental dural punctures and observed no signs of persistent neurological injury in any of our patients. The epidural catheters provided good analgesia perioperatively.

Fatty tissue occupied the tip of the Tuohy needle partially in $16(80 \%)$ of the 20 patients. In 16 patients, the fatty tissue at the needle tip moved and a visible potential cavity expanded at the needle tip through the patients' maximal inspiration. Cross section area of the visible cavity at the needle tip was greater at the maximal inspiratory level than at the resting expiratory level: 12.1 $\pm 6.7 \%$ vs $2.8 \pm 2.1 \%$ (mean $\pm S D, P<0.0001$, Figure 1). Maximal inspiration increased mean cross section area of the visible cavity to $\mathbf{1 2 . 5}$ times greater than that 


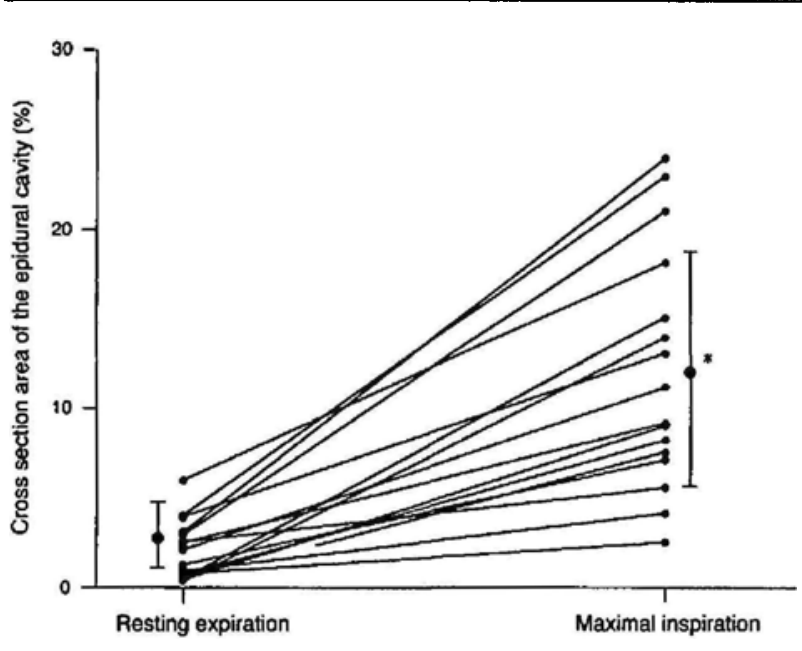

FIGURE 1 Individual data and population changes (mean $\pm \mathrm{SD}$ ) in cross section area of the visible epidural cavity at the tip of the Tuohy needle induced by patients' maximal inspiration. Cross section area of the visible epidural cavity at the needle tip was greater at the maximal inspiratory level than at the resting expiratory level $(P<0.0001)$

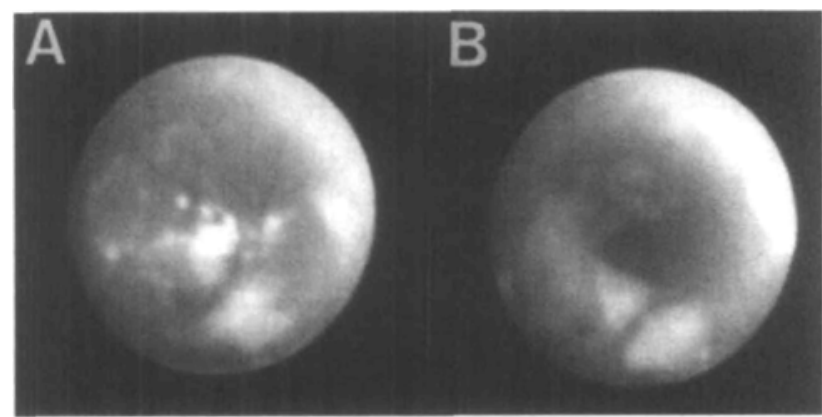

FIGURE 2 Photographs obtained via the fibrescope at the tip of the Tuohy needle. The fatty tissue in the epidural space occupied the tip of the Tuohy needle in a 60-yr-old man (A). When the patient took a deep breath, the epiduroscope revealed a visible cavity beyond the tip of the Tuohy needle after the fatty tissue had been moved (B).

during resting expiration. In the remaining four patients, the potential cavity was already expanded at the overall needle tip area at the resting expiratory level.

Figure 2 shows the finding at the tip of the Tuohy needle in a 60 -yr-old man. The fatty tissue within the epidural space occupied the tip of the Tuohy needle (Figure 2A). When the patient took a deep breath, a potential cavity became visible through the tip of the Tuohy needle after the movement of the fatty tissue (Figure 2B).

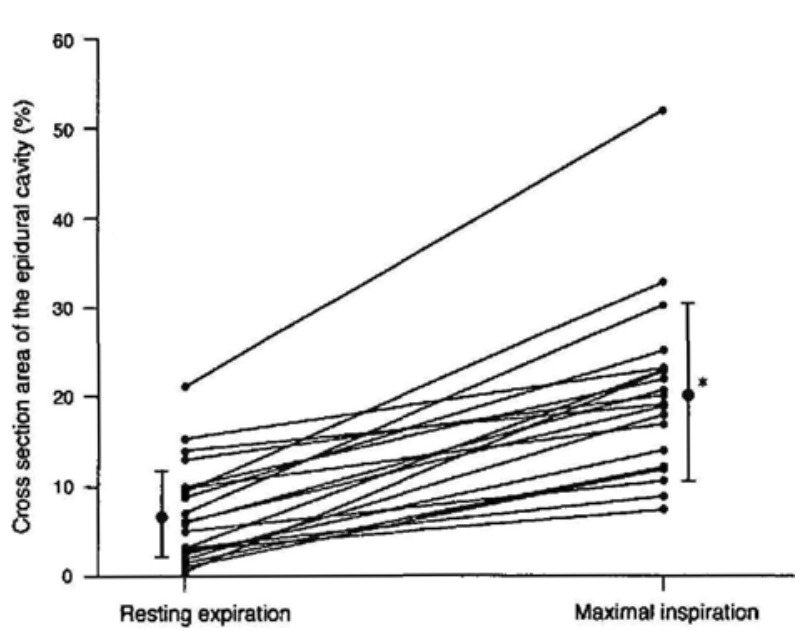

FIGURE 3 Individual data and population changes (mean $\pm S D$ ) in cross section area of the visible epidural cavity at approximately $10 \mathrm{~cm}$ in a cephalad direction within the epidural space induced by patients' maximal inspiration. Cross section area of the visible epidural cavity within the cpidural space was greater at the maximal inspiratory level than at the resting expiratory level $(P<$ 0.0001 )

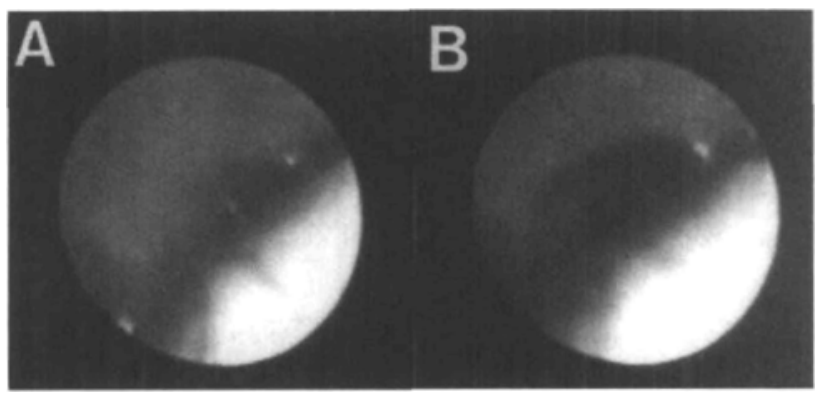

FIGURE 4 Photographs obtained via the fibrescope within the thoracic epidural space in a 68-yr-old woman. The upper part appeared yellow and was identified as fatty tissue, while the lower part appeared as a white membrane and was identified as the dura mater (A). The thoracic epidural space which had already been expanded by the injected air became even more expanded after maximal inspiration in the same patient (B).

The epidural space, which had already been expanded by injected air, became even more expanded during maximal inspiration. Cross section area of the visible cavity at approximately $10 \mathrm{~cm}$ in a cephalad direction from the needle tip within the epidural space was greater at the maximal inspiratory level than at the resting expiratory level: $20.6 \pm 10.0 \%$ ws $7.0 \pm 5.3 \%(\mathrm{P}<$ 0.0001 , Figure 3). Maximal inspiration increased mean 


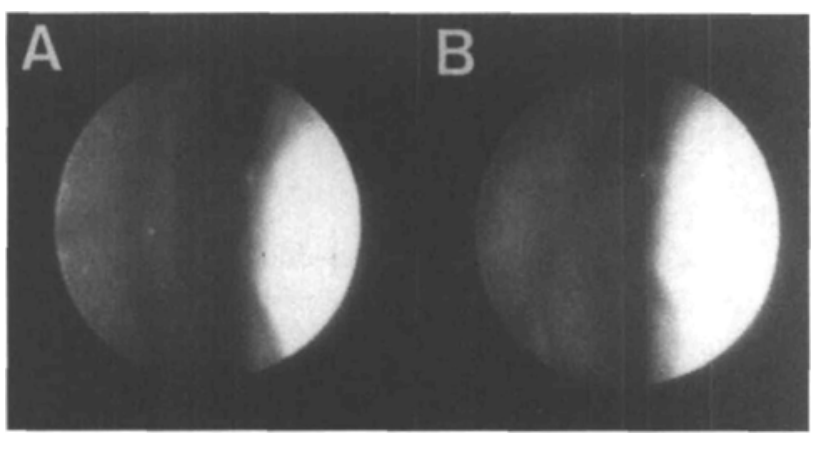

FIGURE 5 Photographs obtained via the fibrescope within the epidural space of a 65 -yr-old woman. The yellow area on the upper part of the photograph was identified as facty tissue with an associated blood vessel (A). The lower part of the photograph appears as a white membrane and was identified as the dura mater. The blood vessel associated with the fatty tissuc collapsed after maximal inspiration (B).

cross section area of the visible cavity to 5.0 times greater than that during resting expiration.

Figure 4 shows the findings of the thoracic epidural space in a 68-yr-old woman. Fatty tissue appeared yellow and was identified in the upper part, while the dura mater appeared as a white membrane and was identified in the lower part (Figure 4A). Fibrous connective tissues were also seen between the dura mater and the fatty rissue. The thoracic epidural space which had already been expanded by the injected air became even more expanded during maximal inspiration in the same patient (Figure 4B).

Figure 5 shows blood vessels within the epidural space in a 65-yr-old woman. The right part of the photograph appeared as a white membrane with blood vessels and was identified as the dura mater (Figure 5A). The yellow area on the left part of the photograph was identified as fatty tissue with a blood vessel. The blood vessel associated with the fatty tissue collapsed during maximal inspiration (Figure 5B).

\section{Discussion}

Epiduroscopic examination showed that the thoracic epidural structures altered during deep breathing. We suggest that the alteration of the epidural structure may assist in the insertion of the epidural catheter.

We found that the thoracic epidural space which had already been expanded by injected air became further expanded by maximal inspiration. The alteration of the epidural space during deep breathing may be due to the acceleration of the negative intrapleural pressure associated with maximal inspiration. When a patient takes a deep inspiration, the intrapleural pressure decreases. The decrease in the intrapleural pressure spreads to the thoracic epidural space through the intervertebral foramina. At the same time, intrathoracic pressure is transmitted to the cerebrospinal fluid pressure $^{13,14}$ and the dural sac can be thought to collapse after a deep inspiration. ${ }^{1,14}$ In addition, our results showed that the blood vessels within the epidural space collapsed after deep inspiration (Figure 5). The decreases in the intrapleural pressure, in the tension of the dural sac and in the tension of the blood vessels may lead to decreases in the epidural pressure. When the epidural pressure decreased, air could be introduced easily into the epidural space since the epidural space had been left open to the atmosphere through the Tuohy needle. Therefore, the thoracic epidural space had become even more expanded during maximal inspiration in this study.

The existence of fatty tissue and fibrous connective tissue within the epidural space may impede catheter passage. Several authors have shown by sagittal midline magnetic resonance imaging, ${ }^{2}$ cryomicrotomy ${ }^{3}$ and epiduroscopy ${ }^{4}$ that fatty tissue exists as segmental parts in the epidural space. Because we used a small amount of air for identifying the epidural space, the injected air may have pulled some of the fatty tissue away from the dura mater, expanded the epidural space and stretched the connective tissues. However, resistance could still have been generated between the catheter tip and the remaining connected fatty tissue. We suggest that the expansion of the potential cavity during deep inspiration makes a path for the catheter and assists in the advancing of the catheter within the epidural space.

In most of our patients, fatty tissue existed at the tip of the Tuohy needle. The fatty tissue occupying the needle tip could also impede the advancement of the catheter. Our results showed that the fatty tissue at the tip of the Tuohy needle moved and a potential cavity became visible during maximal inspiration. We suggest that the movement of fatty tissue at the needle tip, as well as the expansion of the potential cavity at the cephalad direction within the epidural space, may be relevant in reducing resistance during insertion of the epidural catheter during deep breathing.

Our results also showed that the blood vessels within the epidural space collapsed after maximal inspiration. In clinical situations intravascular placement of the epidural catheter may occur. ${ }^{15,16}$ The insertion of the catheters during maximal inspiration may prevent the intravascular placement of the epidural catheter because the blood vessels collapse and the epidural space becomes even more expanded after maximal inspiration. 
Several factors may have influenced the results of this study. The degree of deep breathing may have varied from patient to patient. We suggest that changes in epidural pressure during deep breathing result in epidural structure changes. ${ }^{17}$ If a parient does not achieve maximal inspiration, the changes in the epidural structures will be less. Although we asked the patients to take a deep breath to the maximal inspiratory level, confirmed by the patient's performance, we did not measure the volumes and capacities of breathing. Therefore, the different breathing depths may have lead to the changes in the structure within the epidural space.

We suggest that the considerable changes observed in this study may only be evident when the epidural space interacts with the atmosphere. On the assumption that the epidural space had not interacted with atmosphere, the epidural space would not expand so clearly even if the epidural pressure decrease. In addition, the amount of air used for the loss-of-resistance method may affect our results because the injected air was supposed to pull some of the fatty tissue away from the dura mater. If we were to use an amount of air more or less than $5 \mathrm{ml}$ for the loss-of-resistance method, it is not known how the epidural structure changes during deep breathing. However, the epiduroscopic procedure used in this study is close to the common technique of inserting an epidural catheter. We believe our results show that deep breathing facilitates epidural catheter insertion.

It has been suggested that, in the lower thoracic and lumbar segments, the epidural space is transversely divided into anterior, dorsal and dorsolateral compartments. ${ }^{18,19}$ In this study, the tip of the Tuohy needle was inserted into the epidural space as close to the midline as possible and no evidence of nerve irritation was detected. If the epiduroscope had advanced through the dorsal compartment into the other compartment, the epiduroscope would have touched the nerve roots and nerve irritation would have occurred. ${ }^{4}$ Because this did not happen, the changes in the findings observed in this study presumably confirmed the dorsal compartment within the epidural space.

Before starting this study, we tried to examine the epidural space after the loss-of-resistance method with saline. Because the saline adhered on the tip of the fibrescope, we could not obtain any clear view of the epidural space. In contrast, we could obtain a clear view of the epidural space after injecting air. Therefore, we decided to identify the epidural space using the loss-of-resistance method with air and to minimize the amount of air to $5 \mathrm{ml}$ for this study.

In conclusion, epiduroscopy showed that the tho- racic epidural structures alter during deep breathing. Deep breathing may be a strategy for assistance in epidural catheter insertion.

\section{References}

1 Gutsche BB. How to make an epidural work. In: American Society of Anesthesiologists (Ed.). 45th Annual Refresher Course Lectures and Clinical Update Program, Philadelphia: JB Lippincott, 1994: 411(411)-411(417).

2 Westbrook JL, Renowden SA, Carrie LES. Study of the anatomy of the extradural region using magnetic resonance imaging. Br J Anaesth 1993; 71: 495-8.

3 Hogan $Q H$. Epidural anatomy examined by cryomicrotome section. Reg Anesth 1996; 21: 395-406.

4 Igarashi T, Hirabayashi $\Upsilon$, Shimizu R, Saitoh $K$, Fukuda $H$. Thoracic and lumbar extradural structure examined by extraduroscope. Br J Anaesth 1998; 81: 121-5.

5 Blomberg RG, Olsson SS. The lumbar epidural space in patients examined with epiduroscopy. Anesth Analg $1989 ; 68: 157-60$.

6 Harrison GR. The epidural space (Letter). Anaesthesia 1989; 44: 361-2.

7 Parkin IG, Harrison GR. The topographical anatomy of the lumbar epidural space. J Anat 1985; 141: 211-7.

8 Usubiaga JE, Moya F, Usubiaga LE. Effect of thoracic and abdominal pressure changes on the epidural space pressure. Br J Anaesth 1967; 39: 612-8.

9 Blomberg $R$. The dorsomedian connective tissue band in the lumbar epidural space of humans: an anatomical study using epiduroscopy in autopsy cases. Anesth Analg 1986; 65: 747-52.

10 Igarashi $T$, Hirabayashi $Y$, Shimizu $R$, et al. Inflammatory changes after extradural anaesthesia may affect the spread of local anaesthetic within the extradural space. Br J Anaesth 1996; 77: 347-51.

11 Igarashi $T$, Hirabayashi $Y$, Shimizu $R$, Saitob $K$, Fukuda $H$, Mitsuhata $H$. The lumbar extradural structure changes with increasing age. Br J Anaesth 1997; 78: 149-52.

12 Otomo $N$, Hirota $K$, Hashimoto $Y$, et al. Measurement of bronchodilatation using a superfine fibreoptic bronchoscope. Br J Anaesth 1997; 78: 583-5.

13 Koebler RC, Chandra N, Guerci AD, et al. Augmentation of cerebral perfusion by simultaneous chest compression and lung inflation with abdominal binding after cardiac arrest in dogs. Circulation 1983; 67: 266-75.

14 Urayama $K$. Origin of lumbar cerebrospinal fluid pulse wave. Spine 1994; 19: 441-5. 
15 Blouin RT, Ruby ST, Gross JB. Determination of intravascular migration of an epidural catheter using the air technique. Anesthesiology 1993; 79: 1427-9.

16 Bush DJ, Kramer DP. Intravascular migration of an epidural catheter during postoperative patient-controlled epidural analgesia. Anesth Analg 1993; 76: 1150-1.

17 Bromage PR. Epidural pressures. In: Bromage PR (Ed.). Epidural Analgesia, Philadelphia: WB Saunders, 1978: 160-75.

18 Seeling W, Tomczak R, Merk J, Mrakovi N. Comparison of conventional and computed tomographic epidurography with contrast medium using thoracic epidural catheters. (German) Anaesthesist 1995; 44: 24-36.

19 Savolaine ER, Pandya JB, Greenblatt SH, Conover SR. Anatomy of the human lumbar epidural space: New insights using CT-epidurography. Anesthesiology 1988; 68: $217-20$. 